\title{
Oxymatrine suppresses proliferation and facilitates apoptosis of human ovarian cancer cells through upregulating microRNA-29b and downregulating matrix metalloproteinase-2 expression
}

\author{
JINGWEI LI, KAILEI JIANG and FUJIE ZHAO \\ Department of Obstetrics and Gynecology, Shengjing Hospital of China Medical University, \\ Shenyang, Liaoning 110004, P.R. China
}

Received September 9, 2014; Accepted May 21, 2015

DOI: $10.3892 / \mathrm{mmr} .2015 .3977$

\begin{abstract}
Oxymatrine, an alkaloid extracted from medicinal plants of the genus Sophora, has a wide range of pharmacological effects. Previous studies have revealed that oxymatrine can inhibit proliferation and metastasis of tumor cells through reducing matrix metalloproteinase-2 (MMP-2) mRNA expression. However, the expression of MMP-2 in ovarian cancer is significantly higher than that in normal ovaries. Furthermore, the expression of microRNA-29b (miR-29b) in ovarian carcinoma is significantly lower than that in normal ovaries. Therefore, MMP-2 and miR-29b are tumor suppressor factors involved in ovarian cancer. To evaluate the anti-cancer effects of oxymatrine the OVCAR-3 ovary cancer cell line was treated with oxymatrine at the concentrations of $0,0.5,1$ and $2 \mathrm{mg} / \mathrm{ml}$. Assessment of the proliferation and apoptosis of OVCAR-3 cells showed that oxymatrine had an inhibitory effect on ovarian cancer cells. Furthermore, oxymatrine decreased the protein levels of MMP-2 and increased the expression levels of miR-29b in OVCAR-3 cells. Through transfection of miR-29b precursor into OVCAR-3 cells, it was demonstrated that miR-29b regulated MMP-2 expression in OVCAR-3 cells. In addition, anti-miR-29b antibodies were used to verify that the apoptotic effect of oxymatrine was due to upregulating miR-29b and downregulating MMP-2 expression. These results showed that oxymatrine suppresses the proliferation and facilitates apoptosis of human ovarian cancer cells through upregulating miR-29b and downregulating MMP-2 expression.
\end{abstract}

Correspondence to: Dr Fujie Zhao, Department of Obstetrics and Gynecology, Shengjing Hospital of China Medical University, 36 Sanhao Street, Heping, Shenyang, Liaoning 110004, P.R. China E-mail: fujiezhaomr@163.com

Key words: oxymatrine, ovarian cancer, microRNA-29b, OVCAR-3 cells, matrix metalloproteinase-2

\section{Introduction}

Ovarian cancer is a type of malignant tumor which has the highest lethality rate among all gynecological diseases, and possesses high invasion ability as well a high potential to form distant metastases (1). The five-year survival rate of patients is as low as $25-30 \%$. Due to the insidious onset and the asymptomatic characteristics in the early stages, $70-80 \%$ of the patients are diagnosed at a late stage, and therefore, the mortality rate ranks first among all gynecological malignancies (2,3). As a part of the hypothalamus-pituitary-ovarian gonadal axis, the ovaries themselves are subject to the regulation of upstream gonadotropins and gonadotropin-releasing hormone, and therefore, regulation of hormone levels is an important mechanism to adjust the incidence of ovarian cancer $(4,5)$.

Matrix metalloproteinase-2 (MMP-2) degrades vascular basement membrane and extracellular matrix, which are major barriers against cancer cell invasion and metastasis; upregulation of MMP-2 in cancer enables tumor cells to break through the barriers and promotes local invasion and distant metastasis of tumor cells $(6,7)$. The mRNA and protein expression levels of MMP-2 in epithelial ovarian cancer are significantly higher than those in normal ovaries, benign ovarian tumors and borderline ovarian tumors (8). MMP-2 overexpression was shown to promote ovarian cancer invasion and metastasis (9).

MicroRNAs (miRs) are short non-coding RNAs, which regulate gene expression in transcription and translation and are involved in a series of important biological processes, including embryonic development in the early stage, cell proliferation, differentiation, apoptosis, fat metabolism and gene expression regulation $(10,11)$. miR-29 has an important role in tumorigenesis, differentiation and tumor development (12). It has been proven that miR-29 expression is downregulated in various human tumor tissues, including lung cancer, hepatocellular carcinoma and prostate cancer. miR-29 has three sub-units: miR-29a, miR-29b and miR-29c (13). miR-29b has been proved to be expressed in breast cancer tissues (14). Expression of miR-29b in epithelial ovarian carcinoma is significantly reduced compared with that in benign ovarian tumor or normal ovarian tissues (15). miR-29b as a tumor suppressor may be involved in epithelial ovarian cancer, as the expression of miR-29b gradually decreases with increasing 
stage; the expression of miR-29b in stage-III-IV epithelial ovarian cancer tissue was shown to be significantly lower than that in stage-I-II ovarian cancer (16).

Oxymatrine (Fig. 1) is an alkaloid extracted from medicinal plants of the genus Sophora, which include bitter beans and broad bean roots, and has a wide range of pharmacological activities, including anti-bacterial, anti-inflammatory, anti-rheumatic, anti-tumor, anti-allergic and immunomodulatory effects $(17,18)$. A large number of studies suggested that oxymatrine can inhibit the proliferation and metastasis of tumor cells, induce apoptosis, cause normal cell differentiation and have anti-tumor activity (17,19-21). Oxymatrine is able to inhibit pancreatic cancer cell invasion and metastasis through significantly reducing MMP-2 mRNA expression $(19,22)$. Furthermore, oxymatrine is able to significantly inhibit liver cancer cell proliferation, induce apoptosis and thus downregulate the expression of signal transducer and activator of transcription 3 (Stat3) and Stat5 mRNA (23).

The present study investigated the inhibitory role of oxymatrine in ovarian cancer cells and studied the underlying molecular mechanisms. For this, the roles of miR-29b and MMP-2 in the effect of oxymatrine on the proliferation and apoptosis of human ovarian cancer cells were investigated.

\section{Materials and methods}

Chemicals and reagents. Oxymatrine (purity, 98\%; SigmaAldrich, St Louis, MO, USA) was dissolved in physiological saline. Dulbecco's modified Eagle's medium (DMEM) and fetal calf serum (FBS) were obtained from Gibco-BRL (Invitrogen Life Technologies, Carlsbad, CA, USA) and Hyclone (GE Healthcare, Little Chalfont, UK), respectively. MTT was purchased from Sigma-Aldrich.

Cell culture. The human ovarian cancer cell line OVCAR-3 was obtained from the Shanghai Cell Bank of the Chinese Academy of Sciences (Shanghai, China). The cells were cultured in medium containing 10\% (v/v) FBS and $100 \mathrm{U}$ penicillin/streptomycin (Invitrogen Life Technologies). Cultured cells were maintained at a temperature of $37^{\circ} \mathrm{C}$ in a humidified atmosphere with $5 \% \mathrm{CO}_{2}$. OVCAR-3 cells were treated with oxymatrine in complete DMEM medium.

Cell viability assay. The viability of OVCAR-3 cells was determined using the MTT assay. OVCAR-3 cells $\left(1.0 \times 10^{3}\right.$ cells/well $)$ were seeded on 96 -well plates at a temperature of $37^{\circ} \mathrm{C}$ in a humidified atmosphere with $5 \% \mathrm{CO}_{2}$. OVCAR-3 cells were incubated with various concentrations of oxymatrine $(0,0.5,1$ and $2 \mathrm{mg} / \mathrm{ml})$ for $48 \mathrm{~h}$. Subsequently, $10 \mu$ MTT (Sigma-Aldrich) was added to each well followed by incubation for $4 \mathrm{~h}$ at a temperature of $37^{\circ} \mathrm{C}$ in a humidified atmosphere with $5 \% \mathrm{CO}_{2}$. The medium was removed and $150 \mu$ dimethylsulfoxide (Invitrogen Life Technologies) was added followed by agitation at room temperature for $10 \mathrm{~min}$. The optical density was the measured at $570 \mathrm{~nm}$ using a microplate reader (Thermo Molecular Devices Co., Union City, NJ, USA).

Caspase-3 activity assay. OVCAR-3 cells were plated at in six-well plates $\left(1.0-2.0 \times 10^{5}\right.$ cells/well) and incubated for $24 \mathrm{~h}$.

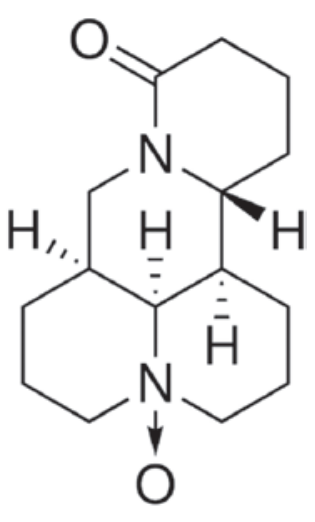

Figure 1. Chemical structure of oxymatrine.

Subsequently, the cells were treated with various concentrations of oxymatrine $(0,0.5,1$ and $2 \mathrm{mg} / \mathrm{ml})$. The activity of caspase-3 was detected using the caspase-3 colorimetric assay kit (KeyGEN, Nanjing, China) following the manufacturer's instructions. An equal amount of total protein extract was incubated at $37^{\circ} \mathrm{C}$ with Ac-DEVD-pNA for the caspase-3 assay for 4-6 h. The change in fluorescence was detected at a wavelength of $405 \mathrm{~nm}$.

Flow cytometry. OVCAR-3 cells (1.0-2.0x $10^{5}$ cells/well) were plated in six-well plates and incubated for $24 \mathrm{~h}$. Subsequently, the cells were treated with various concentrations of oxymatrine $(0,0.5,1$ and $2 \mathrm{mg} / \mathrm{ml})$. In accordance with the manufacturer's instructions, the cells were washed with PBS and collected in buffer solution (BD Biosciences, Franklin Lakes, NJ, USA). The cells were then incubated with Annexin-V-fluorescein isocyanate (FITC) and propidium iodide for $30 \mathrm{~min}$ on ice. Following incubation, the apoptotic cells were detected using a FACSCanto II flow cytometer (Becton Dickinson).

Gelatin zymography assays of MMP-2. In accordance with the manufacturer's instructions, the MMP-2 protein levels of OVCAR-3 cells were analyzed by gelatin zymography assays. $20 \mu$ l of collected media were added to a fresh centrifuge tube with an equal volume of SDS sample buffer (BD Biosciences). The miscible liquids were subjected to $10 \%$ SDS-PAGE (Beyotime Institute of Biotechnology, Jiangsu, China) using an electrophoresis gel impregnated with $0.1 \%$ gelatin (Sigma-Aldrich). After electrophoresis, the gel was washed with $2.5 \%$ Triton $\mathrm{X}-100$ for $0.5-1 \mathrm{~h}$ and incubated in a reaction buffer at $37^{\circ} \mathrm{C}$ for $12 \mathrm{~h}$. After incubation, the gel was stained with $0.05 \%$ Coomassie brilliant blue R-250 (Amresco, Solon, $\mathrm{OH}, \mathrm{USA})$.

Quantitative polymerase chain reaction $(q P C R)$ analysis of miR-29b expression. OVCAR-3 cells were plated on six-well plates (1.0-2.0x $10^{5}$ cells/well) and incubated for $24 \mathrm{~h}$. Then cells were treated with various concentrations of oxymatrine $(0,0.5,1$ and $2 \mathrm{mg} / \mathrm{ml})$. Total RNA was isolated from the cells using TRIzol reagent (Invitrogen Life Technologies), according to the manufacturer's instructions. The RNA was subsequently reverse transcribed into cDNA using the PrimeScript RT Master mix (Takara, Otsu, Japan). In 

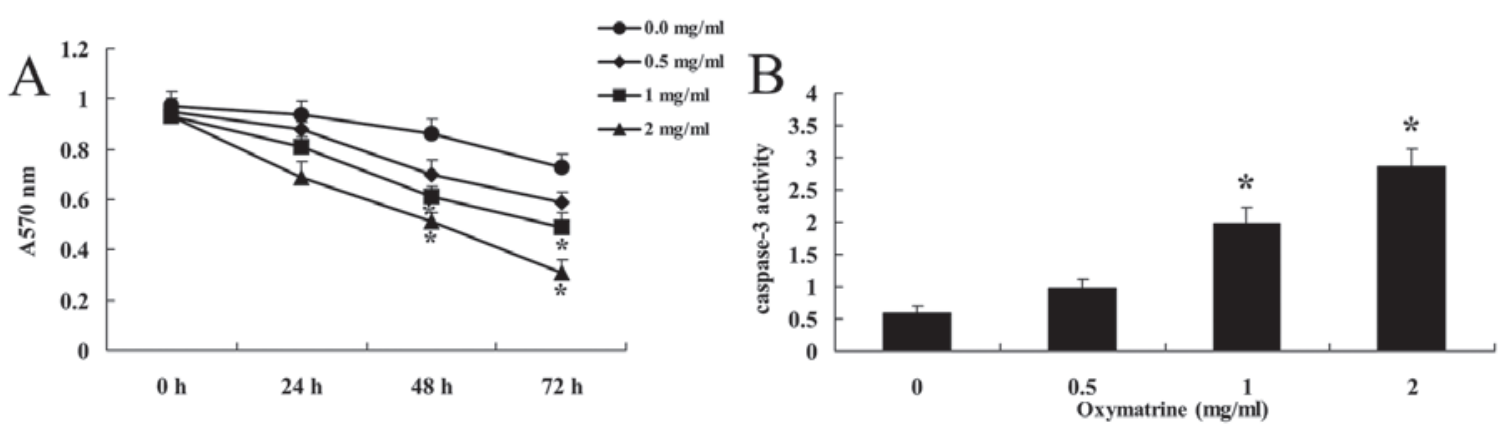

Figure 2. Effect of oxymatrine on OVCAR-3 cell growth. (A) Oxymatrine treatment dose-dependently inhibited OVCAR-3 cell growth. (B) Activity of caspase- 3 was significantly increased after treatment. Values are expressed as the mean \pm standard deviation. ${ }^{*} \mathrm{P}<0.01 \mathrm{compared}$ with $0 \mathrm{mg} / \mathrm{ml} \mathrm{oxymatrine}$ treatment group.
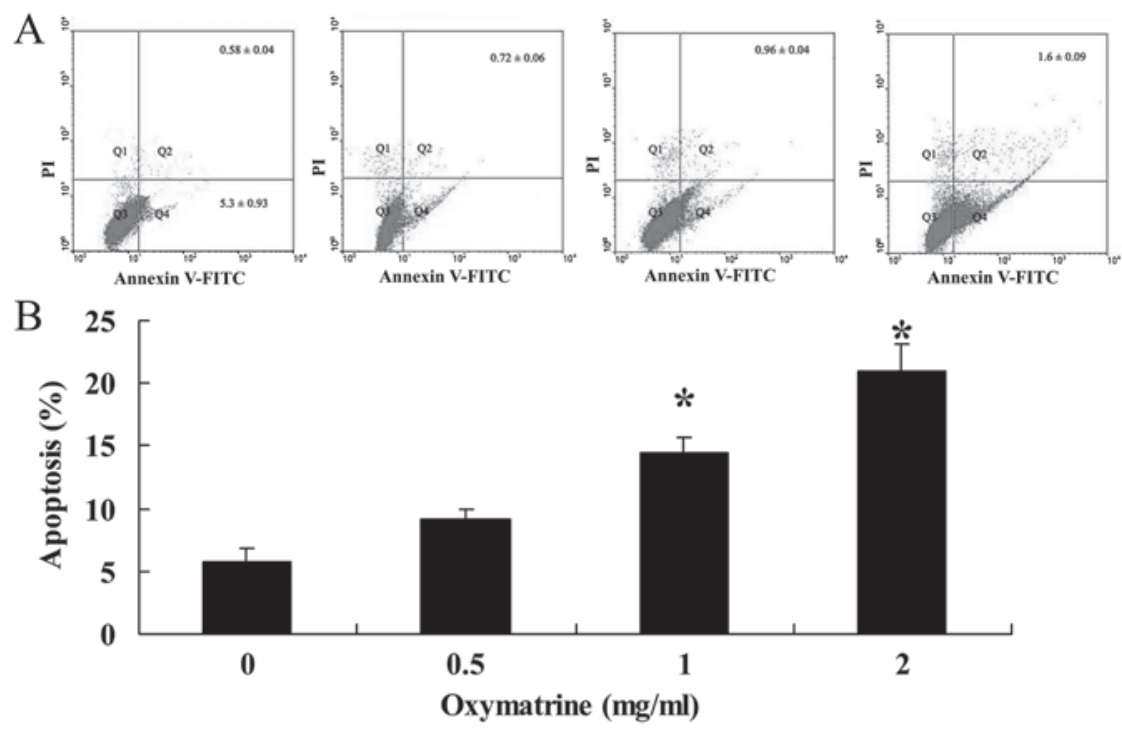

Figure 3. (A) Induction of apoptosis by oxymatrine. (B) Oxymatrine significantly induced apoptosis of OVCAR-3 cells after treatment for $48 \mathrm{~h}$. Values are expressed as the mean \pm standard deviation. ${ }^{*} \mathrm{P}<0.01$ compared with $0 \mathrm{mg} / \mathrm{ml}$ oxymatrine treatment group.

accordance with the manufacturer's instructions, the miR-29b expression levels were detected using the Bulge-Loop miRNA qRT-PCR kit (Guangzhou Ribobio, Guangzhou, China). Cycling conditions were as follows: $95^{\circ} \mathrm{C}$ for $10 \mathrm{~min}$ followed by 35 cycles of $95^{\circ} \mathrm{C}$ for $15 \mathrm{sec}, 56^{\circ} \mathrm{C}$ for $30 \mathrm{sec}$ and $72^{\circ} \mathrm{C}$ for $30 \mathrm{sec}$, and a final elongation at $72^{\circ} \mathrm{C}$ for $7 \mathrm{~min}$, on an ABI 7500 system (Takara). For miR-29b, the primers were as follows: 5'-ACGCAAATTCGTGAAGCGTT-3' and 5'-UAGCACCAUUUGAAAUCAGUGUU-3'. The primers for $\beta$-actin were as follows: 5'-GTTGACATCCGTAAAGACC-3' and 5'-GGAGCCAGGGCAGTAA-3'.

Transfection of miR-29b and anti-miR-29b. The pcDNA-miR-29b precursor and pcDNA-anti-miR-29b were synthesized by Ribobio Biological Tecnology Co. (Shanghai, China). A total of $100 \mathrm{nmol} / \mathrm{l} \mathrm{miR-29b}$ or anti-miR-29b was transfected into the cells with Lipofectamine 2000 (Invitrogen Life Technologies). Twenty-four hours after transfection, cells were treated with various concentrations of oxymatrine $(0,0.5$, 1 and $2 \mathrm{mg} / \mathrm{ml})$.

Statistical analysis. Statistical analysis was performed with SPSS 17.0 software (SPSS, Inc., Chicago, IL, USA). Differences were assessed using analysis of variance or Student's $t$-test. Values are expressed as the mean \pm standard deviation. $\mathrm{P}<0.05$ was considered to indicate a statistically significant difference between values.

\section{Results}

Oxymatrine inhibits OVCAR-3 cell growth and leads to the activation of caspase-3. In the present study, the proliferation of OVCAR-3 cells was measured by using the MTT assay. After treatment with oxymatrine $(0,0.5,1$ and $2 \mathrm{mg} / \mathrm{ml})(24,25)$, the proliferation of OVCAR-3 cells was reduced (Fig. 2A). Treatment with oxymatrine at the concentrations of 1 and $2 \mathrm{mg} / \mathrm{ml}$ significantly inhibited the proliferation at $48 \mathrm{~h}$ and $72 \mathrm{~h}(\mathrm{P}<0.01)$ (Fig. 2A). Furthermore, treatment with oxymatrine $(0,0.5,1$ and $2 \mathrm{mg} / \mathrm{ml})$ at $48 \mathrm{~h}$, increased the activity of caspase-3 (Fig. 2B). Treatment with oxymatrine at the concentrations of 1 and $2 \mathrm{mg} / \mathrm{ml}$ significantly increased caspase activity $(\mathrm{P}<0.01)($ Fig. $2 \mathrm{~B})$.

Oxymatrine induces apoptosis in ovarian cancer cells. After treatment with oxymatrine $(0,0.5,1$ and $2 \mathrm{mg} / \mathrm{ml})$, the apoptotic effect of OVCAR-3 cells was measured by staining 

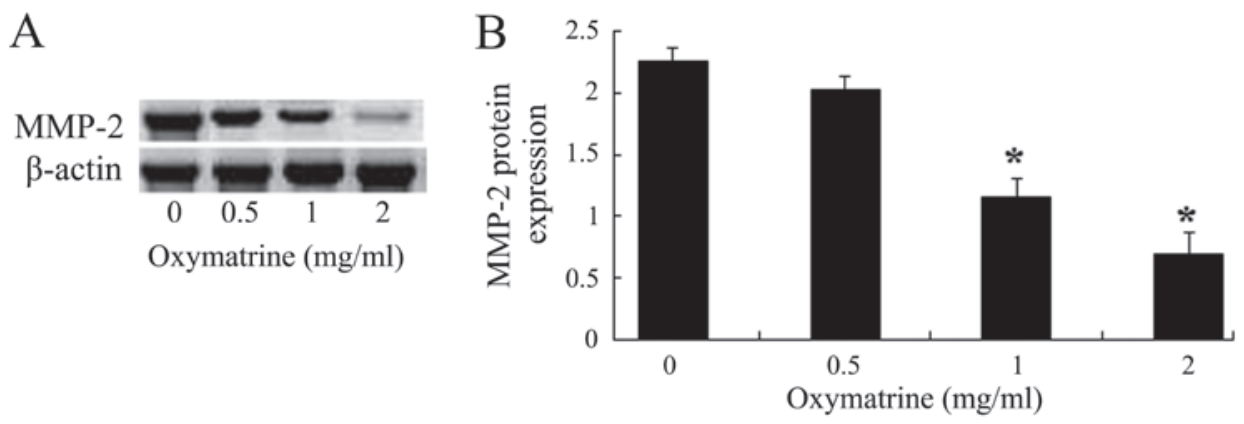

Figure 4. Inhibitory effects of oxymatrine on MMP-2. (A) MMP-2 activity was dose-dependently diminished in OVCAR-3 cells after treatment with oxymatrine $(1 \mathrm{mg} / \mathrm{ml})$ for $48 \mathrm{~h}$ as indicated by gelatin zymography assays. (B) Quantified MMP-2 protein levels. Values are expressed as the mean \pm standard deviation. ${ }^{*} \mathrm{P}<0.01$ compared with $0 \mathrm{mg} / \mathrm{ml}$ oxymatrine treatment group. MMP, matrix metalloproteinase.

with Annexin-V-FITC/propidium iodide for $48 \mathrm{~h}$ followed by flow-cytometric analysis. Treatment with oxymatrine at the concentrations of 1 and $2 \mathrm{mg} / \mathrm{ml}$ significantly increased the apoptotic effect $(\mathrm{P}<0.01)$ (Fig. 3).

Oxymatrine decreases the expression of MMP-2. After treatment with oxymatrine $(0,0.5,1$ and $2 \mathrm{mg} / \mathrm{ml})$ for $48 \mathrm{~h}$, the protein levels of MMP-2 in OVCAR-3 cells were assessed using gelatin zymography assays (Fig. 4A). Treatment with oxymatrine at the concentrations of 1 and $2 \mathrm{mg} / \mathrm{ml}$ significantly decreased the protein levels of MMP-2 $(\mathrm{P}<0.01)$ (Fig. 4B).

Oxymatrine stimulates $m i R-29 b$ expression. After treatment with oxymatrine $(0,0.5,1$ and $2 \mathrm{mg} / \mathrm{ml})$, the miR-29b expression levels of OVCAR-3 cells were assessed using PCR analysis at $48 \mathrm{~h}$. The miR-29b expression levels of OVCAR-3 cells were increased (Fig. 5). Treatment with oxymatrine at the concentrations of 1 and $2 \mathrm{mg} / \mathrm{ml}$ significantly increased the miR-29b expression levels $(\mathrm{P}<0.01)$ (Fig. 5).

Overexpression of miR-29b decerases MMP-2 expression. To determine whether miR-29b regulates MMP-2 expression in OVCAR-3 cells, the protein levels of MMP-2 in OVCAR-3 cells were assessed following transfection of the cells with miR-29b precursor. The effect of miR-29b precursor on the miR-29b expression was determined by qPCR analysis. The results indicated that transfection with miR-29b precursor significantly elevated the expression of miR-29b in OVCAR-3 cells $(\mathrm{P}<0.01)$ (Fig. 6A) and obviously decreased MMP-2 expression (Fig. 6B).

The anti-proliferative effect of oxymatrine is mediated via miR-29b, which negatively regulates MMP-2 expression. The anti-miR-29b vector was employed to investigate the role of miR-29b in the effect of oxymatrine on the growth inhibition of OVCAR-3 cells. The results indicated that anti-miR-29b efficiently penetrated into OVCAR-3 cells and significantly reduced the expression of miR-29b (Fig. 7A). Furthermore, anti-miR-29b significantly reduced the effect of oxymatrine $(1 \mathrm{mg} / \mathrm{ml})$ on the apoptosis (Fig. 7B) and proliferation (Fig. 7C) of OVCAR-3 cells at $48 \mathrm{~h}$ and neutralized the inhibitory effect of oxymatrine $(1 \mathrm{mg} / \mathrm{ml})$ through downregulating MMP-2 activity (Fig. 7D) in OVCAR-3 cells.

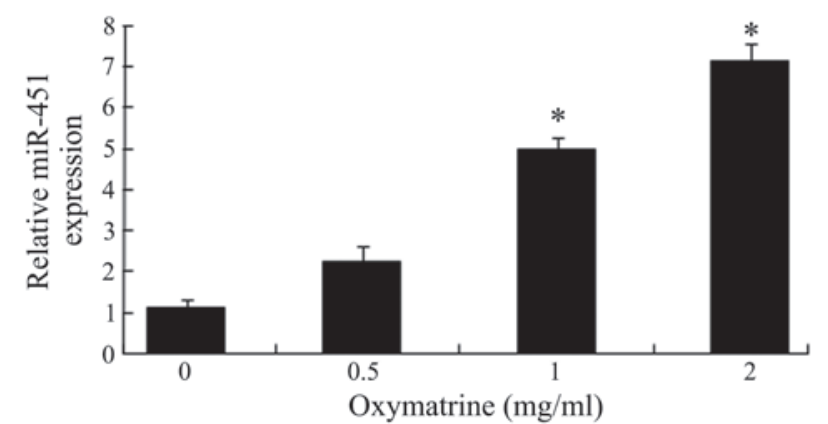

Figure 5. Oxymatrine stimulates miR-29b expression. Oxymatrine treatment increases the expression of miR-29b in a dose-dependent way. Values are expressed as the mean \pm standard deviation. ${ }^{*} \mathrm{P}<0.01$ compared with $0 \mathrm{mg} / \mathrm{ml}$ oxymatrine treatment group. miR, microRNA.

\section{Discussion}

To the best of our knowledge, the present study was the first to investigate the inhibitory effects of oxymatrine on ovarian cancer cells. Oxymatrine significantly reduced the proliferation and induced apoptosis of OVCAR-3 cells. Furthermore, oxymatrine significantly decreased the MMP-2 proteins level and increased the miR-29b expression levels in ovarian cancer cells. The results suggested that the apoptotic effect of oxymatrine was due to upregulating miRNA-29b and downregulating MMP-2 expression, confirmed by reversal of this effect following transfection with anti-miR-29b.

Ovarian cancer is a malignant disease with multiple gene mutations and stages; the specific cancer-associated gene mutations are important factors regarding the occurrence, development and prognosis of ovarian cancer (17). Oxymatrine is an alkaloid with numerous pharmacological activities. Oxymatrine inhibits the proliferation of tumor cells by inhibiting their DNA synthesis, affecting their cell cycle (26). MMP-2 is capable of degrading collagen, gelatin, laminin, fibronectin, elastin, proteoglycans and other important components of the extracellular matrix and promoting the invasion, metastasis and angiogenesis of tumor cells through degrading the basement membrane and remodeling influential tissues of the extracellular matrix $(7,27)$. In the present study, the proliferation of OVCAR-3 cells was significantly inhibited after treatment with oxymatrine (1 and $2 \mathrm{mg} / \mathrm{ml}$ ) at 48 and $72 \mathrm{~h}$. It was therefore suggested that oxymatrine may be suitable for the treatment of ovarian cancer. 

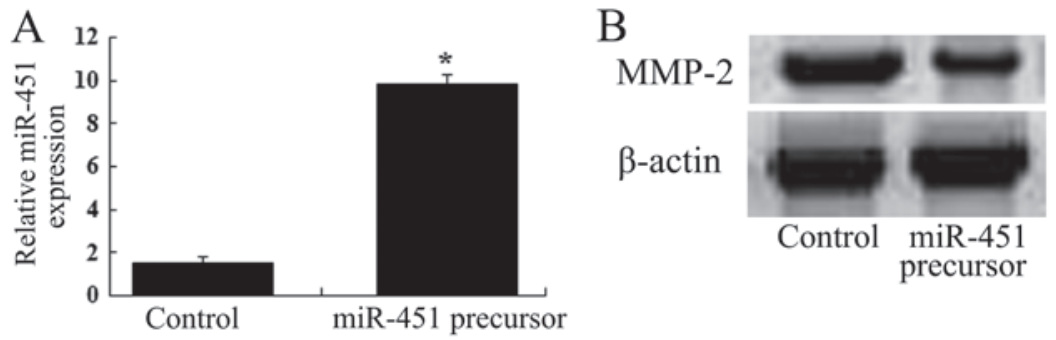

Figure 6. Overexpression of miR-29b suppresses MMP-2 expression. (A) miR-29b precursor significantly elevated the expression of miR-29. (B) Transfection with miR-29b precursor decreased MMP-2 protein expression. Values are expressed as the mean \pm standard deviation. " $\mathrm{P}<0.01 \mathrm{compared}$ with $0 \mathrm{mg} / \mathrm{ml}$ oxymatrine treatment group. MMP, matrix metalloproteinase; miR, microRNA.

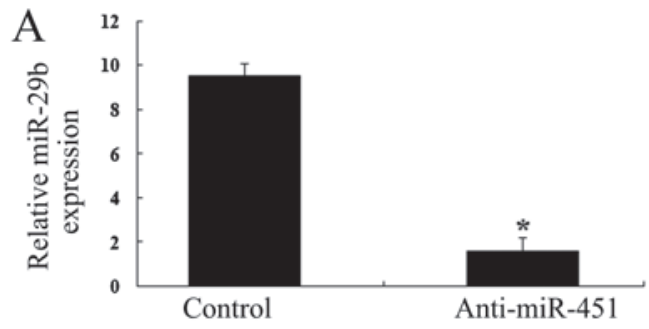

$\mathrm{C}$

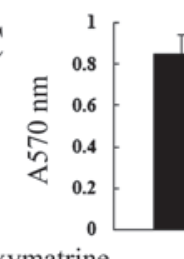

Oxymatrine

Negation control -

Anti-miR-451
$\mathrm{B}$

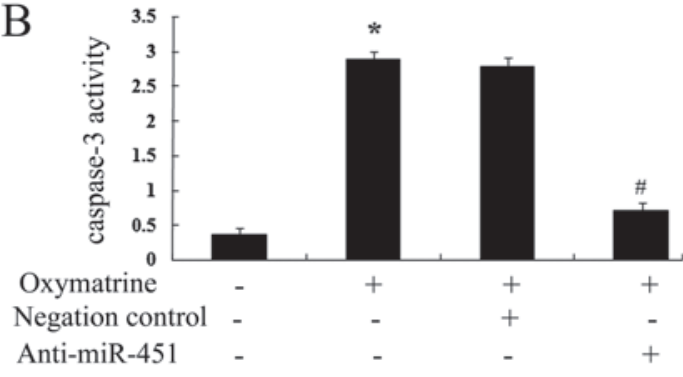

$\mathrm{D}$

Oxymatrine

Negation control

Anti-miR-451

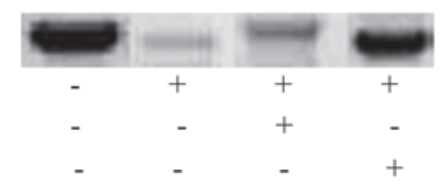

Figure 7. Effects of miR-29b elimination on cell proliferation and apoptosis. (A) Anti-miR-29b significantly diminished the expression of miR-29b in OVCAR-3 cells. (B) After treatment with oxymatrine $(1 \mathrm{mg} / \mathrm{ml})$ for $48 \mathrm{~h}$, anti-miR-29b evidently promoted the cell proliferation. (C) After treatment with oxymatrine $(1 \mathrm{mg} / \mathrm{ml})$ for $48 \mathrm{~h}$, anti-miR-29b evidently inhibited apoptosis of OVCAR-3 cells. (D) Anti-miR-29b significantly increased matrix metalloproteinase-2 activity in OVCAR-3 cells after oxymatrine $(1 \mathrm{mg} / \mathrm{ml})$ treatment at $48 \mathrm{~h}$. Values are expressed as the mean \pm standard deviation. ${ }^{*} \mathrm{P}<0.01$ compared with $0 \mathrm{mg} / \mathrm{ml}$ oxymatrine treatment group, and ${ }^{~} \mathrm{P}<0.01$ compared with oxymatrine-treated group transfected with negative control; miR, microRNA.

Oxymatrine induces apoptosis of tumor cells by affecting the expression of genes associated with tumor cells and inhibiting the activity of associated enzymes (28). High-level expression of MMP-2 has been found in numerous types of tumor tissue, and is associated with the tumor's invasiveness. Oxymatrine was shown to significantly inhibit of the invasion of MDA-MB-231 cells by inhibiting the activation of MMP-2/MMP-9 (22). Oxymatrine can dose-dependently inhibit the proliferation of cancer cells. As for different types of tumor cell, the difference in the effective concentration is relatively large, with the effective concentration ranging from 0.2 to $16 \mathrm{mmol} / \mathrm{l}$ (29). In the present study, the effects of oxymatrine on the apoptosis and caspase-3 activity in ovarian cancer cells were detected using the flow-cytometric analysis and a caspase-3 colorimetric assay kit, respectively. The results showed that oxymatrine (1 and $2 \mathrm{mg} / \mathrm{ml}$ ) significantly increased the apoptosis of OVCAR-3 cells at $48 \mathrm{~h}$. Furthermore, oxymatrine significantly decreased the MMP-2 protein levels in ovarian cancer cells, as indicated by gelatin zymography assays.

miRNAs are non-coding, single-stranded RNAs with a low molecular weight, which commonly occur in eukaryotic cells (10). Cell proliferation, differentiation and apoptosis are regulated by the degradation of target mRNAs or inhibition of translation, and participate in processes involved in ontogeny, body metabolism and tumor development (12). Members of the miR-29 family were shown to promote the development of breast and colon cancer by inducing apoptosis (30). miR-29b may also increase the sensitivity of cells to apoptosis by inhibiting the expression of myeloid cell leukemia 1 in cholangiocarcinoma cells and promote tumorigenesis, indicating that miR-29 is closely associated with tumor development (30). The expression of miR-29b in epithelial ovarian cancer patients with lymph node metastasis was found to be significantly lower than that in patients without lymph node metastasis, which indicates that the low expression of miR-29b and the metastasis of ovarian cancer are closely associated $(15,31)$. The present study demonstrated that oxymatrine increased the expression of miR-29b in OVCAR-3 cells using qPCR analysis. Furthermore, miR-29b was found to regulate MMP-2 expression of OVCAR-3 cells through transfection of miR-29b precursor into OVCAR-3 cells. In addition, anti-miR-29b was used to verify that the apoptotic effect of oxymatrine was due 
to upregulating miRNA-29b and downregulating MMP-2 expression.

In the present study, oxymatrine treatment $(1$ and $2 \mathrm{mg} / \mathrm{ml}$ for 48 and $72 \mathrm{~h}$ ) was shown to significantly inhibit the proliferation of OVCAR-3 cells. Furthermore, oxymatrine significantly increased the apoptosis and the activity of caspase- 3 in OVCAR-3 cells. In addition, oxymatrine ( $1 \mathrm{mg} / \mathrm{ml})$ decreased the protein levels of MMP-2 and increased the expression of miR-29b in OVCAR-3 cells at $48 \mathrm{~h}$. Through transfection of miR-29b precursor into OVCAR-3 cells and treatment with oxymatrine $(1 \mathrm{mg} / \mathrm{ml})$ for $48 \mathrm{~h}$, it was indicated that $\mathrm{miR}-29 \mathrm{~b}$ regulates MMP-2 expression in OVCAR-3 cells. Furthermore, anti-miR-29b was used to verify that the apoptotic effect of oxymatrine was mediated through the upregulation of miR-29b and downregulation of MMP-2 expression after treatment with oxymatrine $(1 \mathrm{mg} / \mathrm{ml})$ for $48 \mathrm{~h}$. These results showed that oxymatrine suppresses the proliferation and facilitates apoptosis of human ovarian cancer cells through upregulating miR-29b and downregulating MMP-2 expression.

\section{References}

1. Kim SI, Kim HS, Kim TH, Suh DH, Kim K, No JH, Chung HH, Kim YB and Song YS: Impact of underweight after treatment on prognosis of advanced-stage ovarian cancer. J Immunol Res 2014: 349546, 2014.

2. Barber A, Zhang T and Sentman CL: Correction: immunotherapy with chimeric NKG2D receptors leads to long-term tumor-free survival and development of host antitumor immunity in murine ovarian cancer. J Immunol 193: 1513, 2014.

3. Muralidhar GG and Barbolina MV: Chemokine receptors in epithelial ovarian cancer. Int J Mol Sci 15: 361-376, 2013.

4. Shen CC, Kang YH, Zhao M, He Y, Cui DD, Fu YY, Yang LL and Gou LT: WNT16B from ovarian fibroblasts induces differentiation of regulatory T cells through $\beta$-catenin signal in dendritic cells. Int J Mol Sci 15: 12928-12939, 2014.

5. Liu J, Li J, Zhang JF and Xin XY: Combination of fenretinide and selenite inhibits proliferation and induces apoptosis in ovarian cancer cells. Int J Mol Sci 14: 21790-21804, 2013.

6. Ekinci T, Ozbay PO, Yiğit S, Yavuzcan A, Uysal S and Soylu F: The correlation between immunohistochemical expression of MMP-2 and the prognosis of epithelial ovarian cancer. Ginekol Pol 85: 121-130, 2014.

7. Grelewski PG and Bar JK: The role of $\mathrm{p} 53$ protein and MMP-2 tumor/stromal cells expression on progressive growth of ovarian neoplasms. Cancer Invest 31: 472-479, 2013.

8. Su Y, Gao L, Teng L, Wang Y, Cui J, Peng S and Fu S: Id1 enhances human ovarian cancer endothelial progenitor cell angiogenesis via PI3K/Akt and NF- $\mathrm{B} / \mathrm{MMP}-2$ signaling pathways. J Transl Med 11: 132, 2013.

9. Laios A, Mohamed BM, Kelly L, Flavin R, Finn S, McEvoy L, Gallagher M, Martin C, Sheils O, Ring M, et al: Pre-treatment of platinum resistant ovarian cancer cells with an MMP-9/MMP-2 inhibitor prior to cisplatin enhances cytotoxicity as determined by high content screening. Int J Mol Sci 14: 2085-2103, 2013.

10. Wu DW, Hsu NY, Wang YC, Lee MC, Cheng YW, Chen CY and Lee H: c-Myc suppresses microRNA-29b to promote tumor aggressiveness and poor outcomes in non-small cell lung cancer by targeting FHIT. Oncogene 34: 2072-2082, 2015.

11. Parpart S, Roessler S, Dong F, Rao V, Takai A, Ji J, Qin LX, Ye QH, Jia HL, Tang ZY, et al: Modulation of miR-29 expression by $\alpha$-fetoprotein is linked to the hepatocellular carcinoma epigenome. Hepatology 60: 872-883, 2014.

12. Wu Z, Huang X, Huang X, Zou Q and Guo Y: The inhibitory role of Mir-29 in growth of breast cancer cells. J Exp Clin Cancer Res 32: 98, 2013.
13. Tan M, Wu J and Cai Y: Suppression of Wnt signaling by the miR-29 family is mediated by demethylation of WIF-1 in non-small-cell lung cancer. Biochem Biophys Res Commun 438: 673-679, 2013.

14. Wang C, Bian Z, Wei D and Zhang JG: miR-29b regulates migration of human breast cancer cells. Mol Cell Biochem 352: 197-207, 2011.

15. Yu PN, Yan MD, Lai HC, Huang RL, Chou YC, Lin WC, Yeh LT and Lin YW: Downregulation of miR-29 contributes to cisplatin resistance of ovarian cancer cells. Int J Cancer 134: 542-551, 2014.

16. Creighton CJ, Hernandez-Herrera A, Jacobsen A, Levine DA, Mankoo P, Schultz N, Du Y, Zhang Y, Larsson E, Sheridan R, et al: Integrated analyses of microRNAs demonstrate their widespread influence on gene expression in high-grade serous ovarian carcinoma. PLoS One 7: e34546, 2012.

17. Wu XS, Yang T, Gu J, Li ML, Wu WG, Weng H, Ding Q, Mu JS, Bao RF, Shu YJ, et al: Effects of oxymatrine on the apoptosis and proliferation of gallbladder cancer cells. Anticancer Drugs 25: 1005-1015, 2014

18. Yang Z, Yin R, Cong Y, Yang Z, Zhou E, Wei Z, Liu Z, Cao Y and Zhang N: Oxymatrine lightened the inflammatory response of LPS-induced mastitis in mice through affecting NF- $\mathrm{BB}$ and MAPKs signaling pathways. Inflammation 37: 2047-2055, 2014.

19. Zhang Y, Piao B, Zhang Y, Hua B, Hou W, Xu W, Qi X, Zhu X, Pei Y and Lin H: Oxymatrine diminishes the side population and inhibits the expression of $\beta$-catenin in MCF-7 breast cancer cells. Med Oncol 28 (Suppl 1): S99-S107, 2011.

20. Zhang Y, Liu H, Jin J, Zhu X, Lu L and Jiang H: The role of endogenous reactive oxygen species in oxymatrine-induced caspase-3-dependent apoptosis in human melanoma A375 cells. Anticancer Drugs 21: 494-501, 2010.

21. Wu C, Huang W, Guo Y, et al: Oxymatrine inhibits the proliferation of prostate cancer cells in vitro and in vivo. Mol Med Rep 11: 4129-4134, 2015.

22. Chen H, Zhang J, Luo J, Lai F, Wang Z, Tong H, Lu D, Bu H, Zhang $\mathrm{R}$ and Lin S: Antiangiogenic effects of oxymatrine on pancreatic cancer by inhibition of the NF- $\kappa B$-mediated VEGF signaling pathway. Oncol Rep 30: 589-595, 2013.

23. Ho JW, Ngan Hon PL and Chim WO: Effects of oxymatrine from Ku Shen on cancer cells. Anticancer Agents Med Chem 9: 823-826, 2009.

24. Dong XQ, Du Q, Yu WH, Zhang ZY, Zhu Q, Che ZH, Chen F, Wang $\mathrm{H}$ and Chen J: Anti-inflammatory effects of oxymatrine through inhibition of nuclear factor-kappa $B$ and mitogen-activated protein kinase activation in lipopolysaccharide-induced BV2 Microglia Cells. Iran J Pharm Res 12: 165-174, 2013.

25. Ling Q, Xu X, Wei X, Wang W, Zhou B, Wang B and Zheng S: Oxymatrine induces human pancreatic cancer PANC-1 cells apoptosis via regulating expression of Bcl-2 and IAP families, and releasing of cytochrome c. J Exp Clin Cancer Res 30: 66, 2011.

26. Seo JM, Park S and Kim JH: Leukotriene B4 receptor-2 promotes invasiveness and metastasis of ovarian cancer cells through signal transducer and activator of transcription 3 (STAT3)-dependent up-regulation of matrix metalloproteinase 2. J Biol Chem 287: 13840-13849, 2012.

27. Li LQ, Li XL, Wang L, Du WJ, Guo R, Liang HH, Liu X, Liang DS, Lu YJ, Shan HL, et al: Matrine inhibits breast cancer growth via miR-21/PTEN/Akt pathway in MCF-7 cells. Cell Physiol Biochem 30: 631-641, 2012.

28. Zhang Y, Sun S, Chen J, Ren P, Hu Y, Cao Z, Sun H and Ding Y: Oxymatrine induces mitochondria dependent apoptosis in human osteosarcoma MNNG/HOS cells through inhibition of PI3K/Akt pathway. Tumour Biol 35: 1619-1625, 2014.

29. Gong J, Li J, Wang Y, Liu C, Jia H, Jiang C, Wang Y, Luo M, Zhao H, Dong L, et al: Characterization of microRNA-29 family expression and investigation of their mechanistic roles in gastric cancer. Carcinogenesis 35: 497-506, 2014.

30. Jiang H, Zhang G, Wu JH and Jiang CP: Diverse roles of miR-29 in cancer (review). Oncol Rep 31: 1509-1516, 2014.

31. Cittelly DM, Finlay-Schultz J, Howe EN, Spoelstra NS, Axlund SD, Hendricks P, Jacobsen BM, Sartorius CA and Richer JK: Progestin suppression of miR-29 potentiates dedifferentiation of breast cancer cells via KLF4. Oncogene 32: 2555-2564, 2013. 